\title{
Effect of Different Conditions of Growth and Storage on the Cell Counts of Two Lactic Acid Bacteria after Spray Drying in Orange Juice
}

\author{
Joana Barbosa, Sandra Borges and Paula Teixeira * \\ Universidade Católica Portuguesa, CBQF-Centro de Biotecnologia e Química Fina-Laboratório Associado, \\ Escola Superior de Biotecnologia, Rua Arquiteto Lobão Vital, Apartado 2511, 4202-401 Porto, Portugal; \\ joanabastos@sapo.pt (J.B.); sandraferreiraborges@gmail.com (S.B.) \\ * Correspondence: pcteixeira@porto.ucp.pt; Tel.: +351-225-580-001
}

Academic Editor: Antonio Bevilacqua

Received: 15 February 2016; Accepted: 17 March 2016; Published: 29 March 2016

\begin{abstract}
Consumers increasingly require innovative food products with health benefits. Thus, a dried orange juice incorporating probiotics could be a novel challenge. In this context, we investigated whether different sugars added to the culture media used for growth of two lactic acid bacteria contributed to their protection during spray drying in orange juice and subsequent storage under different conditions of temperature, light exposure and water activity. Cell viability during passage through simulated gastro-intestinal conditions was also investigated. Cells grown in culture medium containing fructose resulted in the worst survival rates during storage. High survival was observed for cells grown in the presence of lactose, followed by glucose. The survival of dried bacteria was enhanced at $4{ }^{\circ} \mathrm{C}$, water activity of 0.03 and absence of daylight. For cells grown in standard culture medium and after 12 months of storage at $4{ }^{\circ} \mathrm{C}$ in orange juice powder (about $10^{9} \mathrm{cfu} / \mathrm{mL}$ ), there was a reduction of approximately 2 log-units for both lactic acid bacteria after gastro-intestinal tract passage simulation. Using the conditions of growth and storage investigated, it is possible to improve the survival rate of lactic acid bacteria and produce an orange juice powder with probiotic characteristics with shelf life of at least 12 months.
\end{abstract}

Keywords: gastro-intestinal tract; Lactobacillus plantarum 299v; Pediococcus acidilactici HA-6111-2; probiotic juice; sugars

\section{Introduction}

Development of foods containing probiotic organisms is still an emerging field, due to the continuous demand of consumers for different products with health promoting characteristics [1]. In addition to traditional dairy products, non-dairy probiotic products like fruit juices are a good alternative for consumers who prefer foods low in cholesterol, which are vegetarians or even lactose intolerant [2].

Producing a dried fruit juice incorporating probiotic bacteria through spray drying is a good way to preserve the fruit juice and simultaneously to present an innovative product.

Spray drying has been extensively used to produce powdered foods since it is an economic technique and easy to control and to operate [3]. Dried products are convenient to ship and to store, and have an increased shelf life. A major problem with the spray drying of fruit juices is their viscosity since they are extremely sticky due to the presence of low molecular weight sugars and organic acids in their composition. Moreover, dried juices are highly hygroscopic and present low solubility and low melting point [4]. However, these problems may be overcome through the addition of high molecular weight drying agents, such as maltodextrins. These compounds prevent operational problems during 
spray drying; structural changes, such as crystallization during storage are also minimized $[5,6]$. The prebiotic characteristics of some drying agents, also promotes the beneficial effects of the final products [7].

The viability of probiotic cultures incorporated into fruit juices may be compromised during spray drying; this technique triggers a series of stresses due to high temperatures and dehydration [8]. To be considered probiotic, foods must contain viable probiotic microorganisms in amounts of about $10^{6}-10^{7}$ colony forming unit (cfu)/g at the time of consumption. This level of viable cells must be maintained during passage through the gastro-intestinal tract [9]. It is, therefore, crucial to guarantee the best performance of probiotic cultures, and for this, some factors like the composition of the growth media and the storage conditions should be considered [8]. Many authors have stated that the presence of some carbohydrates in the culture media influence survival of microorganisms during drying and subsequent storage [10-12]. The viability of dried probiotics is also affected by the storage conditions, i.e., temperature, presence of oxygen and moisture $[12,13]$.

This study aimed (1) to investigate the survival of two lactic acid bacteria (LAB, a commercial probiotic and a potential probiotic) during spray drying in orange juice and subsequent storage as affected by the incorporation of different sugars in the culture medium; (2) to investigate the effects of different conditions of temperature, light exposure and water activity on the survival of the two lactic acid bacteria during storage of the dried powders; and (3) to test the ability of both dried lactic acid bacteria to resist during passage through simulated gastro-intestinal conditions at the end of storage time.

\section{Materials and Methods}

\subsection{Origin, Growth and Storage Conditions of LAB Cultures}

Two strains of LAB were used: Lactobacillus plantarum 299v (probiotic culture supplied by Probis Probiotika, Lund, Sweden) and Pediococcus acidilactici HA-6111-2, a potential probiotic [14], deposited in the culture collection of Escola Superior de Biotecnologia.

Cells were grown in de Man, Rogosa \& Sharpe (MRS) agar (Lab M, Bury, UK) at $37^{\circ} \mathrm{C}$ for $24 \mathrm{~h}$ and stored at $-80^{\circ} \mathrm{C}$ in MRS broth (Lab M) containing 30\% ( $\left.v / v\right)$ of glycerol (Sigma, Steinheim, Germany), and sub-cultured twice in MRS broth before use in assays.

\subsection{Spray Drying of Orange Juice Incorporated with $L A B$}

\subsubsection{Orange Juice Preparation}

Ripe oranges grown in Portugal were randomly purchased from local commercial establishments (Porto, Portugal), and stored at room temperature until used (for no more than $24 \mathrm{~h}$ before experiments).

Oranges were squeezed using a domestic juicer and the juice was filtered to prevent obstruction of the spray dryer atomizer. The total soluble solid content of the juice was adjusted to $1.5 \%(w / v)$ using a digital refractometer (model PR-32 $\alpha$ (alpha), Brix 0\%-32\%, Atago U.S.A., Inc., WA, USA) and $2 \%(w / v)$ of the drying agent $10 \mathrm{DE}$ maltodextrin (Sigma) was added (final $\mathrm{pH}$ of about 3.5). This mixture was dissolved with magnetic stirring at $40^{\circ} \mathrm{C}$.

\subsubsection{Preparation of LAB Cultures}

To test the effect that different sugars exerted on the survival capacity of both LAB along storage after spray drying, cells were grown into standard MRS broth or MRS broth modified by replacing $20 \mathrm{~g} / \mathrm{L}$ of glucose by $20 \mathrm{~g} / \mathrm{L}$ of each sugar: fructose, sorbitol, lactose or sucrose [10].

One colony of each LAB, grown in MRS agar at $37^{\circ} \mathrm{C}$ during $24 \mathrm{~h}$, was transferred to standard or modified MRS broth and incubated in the same conditions. These cultures were then transferred (1:100) to new standard or modified MRS broth and incubated at $37^{\circ} \mathrm{C}$ for $24 \mathrm{~h}$ to reach stationary phase. Cells were harvested by centrifugation $\left(8877 \times \mathrm{g}, 10 \mathrm{~min}, 37^{\circ} \mathrm{C}\right.$; Rotina $35 \mathrm{R}$, Hettich, Germany), 
washed twice in sterile quarter strength Ringer's solution (Lab M) and re-suspended to the same volume of the final solution prepared in Section 2.2.1.

Cultures grown in standard MRS and re-suspended in 3.5\% $(w / v)$ of reconstituted skim milk (RSM) powder (Oxoid, Basingstoke, UK) were used as a control.

\subsubsection{Spray Drying}

The drying of orange juice with each LAB culture was performed in a pilot-scale Spray Dryer (Niro Atomizer, Soborg, Denmark) with a vaned wheel rotating at high speed and a concurrent drying chamber $\left(0.8 \mathrm{~m}\right.$ diameter and $0.6 \mathrm{~m}$ height). The solution previously prepared (stirring at $\left.40^{\circ} \mathrm{C}\right)$ was fed into the chamber through a peristaltic pump at a constant flow rate $(25 \mathrm{~mL} / \mathrm{min})$. The inlet and outlet air temperatures were adjusted to $150{ }^{\circ} \mathrm{C}$ and $70{ }^{\circ} \mathrm{C}$, respectively. The dried powders were collected in a single cyclone air separator system. Each experiment was repeated three times.

\subsubsection{Analysis of Powders}

The dried powders were analyzed immediately after spray drying.

- $\quad$ Drying yield (\%)

The drying yield was determined as the \% weight fraction of the total solids contained in the liquid feed that could be recovered from the collecting vessel attached to the bottom of the cyclone.

- Water activity

The water activity of the powders was measured using a water activity meter (Aqualab, Series 3 , Decagon Devices Inc., Pullman, WA, USA) at a constant temperature of $23 \pm 1{ }^{\circ} \mathrm{C}$. Two readings were made for each sample.

\subsubsection{Storage Conditions}

Dried samples were stored at normal atmosphere (air) in open plastic containers, which were placed inside of hermetically closed glass flasks with dried silica gel (Pronalab, Lisbon, Portugal) or saturated aqueous solution of $\mathrm{LiCl}$ (Sigma), to give controlled $\mathrm{a}_{\mathrm{w}}$ values of 0.11 and 0.03 , respectively [13]. Samples were also stored at two different temperatures $\left(4^{\circ} \mathrm{C}\right.$ and room temperature) and in the presence or absence of daylight (hereafter referred to as light; indirect exposure to sunlight, i.e., ca. $12 \mathrm{~h}$ exposure to natural light).

\subsubsection{Enumeration of LAB Cultures}

Enumeration of each LAB, in orange juice or RSM, was performed before and immediately after spray drying and at regular intervals throughout storage. Dried samples were rehydrated to their initial solids concentration in sterile quarter strength Ringer's solution. Each rehydrated sample was homogenized for $1 \mathrm{~min}$ and kept at room temperature for $30 \mathrm{~min}$ and suitable dilutions were plated in duplicate by the drop count technique [15] on MRS agar. Colonies were counted after incubation at $37^{\circ} \mathrm{C}$ for $48 \mathrm{~h}$ and the $\mathrm{cfu} / \mathrm{mL}$ calculated. Microbial counts were transformed to logarithmic reduction using the equation: $\log \left(\mathrm{N} / \mathrm{N}_{0}\right)$, where $\mathrm{N}$ is the microbial cell count at a particular sampling time and $\mathrm{N}_{0}$ is the microbial cell count after spray drying.

\subsection{Gastro-Intestinal Tract Simulation}

\subsubsection{Inoculum}

At the end of the storage period at $4{ }^{\circ} \mathrm{C}$, powders $\left(\mathrm{a}_{\mathrm{w}}\right.$ of 0.03$)$ containing LAB grown in standard MRS were rehydrated to their initial solids concentration in sterile quarter strength Ringer's solution. Cells dried in RSM were used as a control. 


\subsubsection{Simulated Gastro-Intestinal Conditions}

As described by Barbosa et al. [16], aliquots of $0.5 \mathrm{~mL}$ of each inoculum prepared as described above were placed into glass flasks with $49.5 \mathrm{~mL}$ of Buffered Peptone Water (BPW, Lab M) adjusted to $\mathrm{pH} 3.0$ with Hydrochloric Acid (1M HCl, Pronalab) and with 1000 units/mL of a filter sterilized solution of pepsin (Sigma) to simulate the stomach conditions. Samples were taken at time 0 (time of inoculation) and after $30 \mathrm{~min}$ and $60 \mathrm{~min}$ (quick gastric transit simulation) or for a total of $120 \mathrm{~min}$ (slow gastric transit simulation). To simulate the conditions of the small intestine, a sterile solution of bile salts was added (final concentration of $0.3 \%(w / v)$, Pronadisa), after increasing the $\mathrm{pH}$ from 3.0 to 7.0 with a sterile solution of Sodium Hydroxide $(1 \mathrm{M} \mathrm{NaOH}$, Pronalab). Again, samples were taken at time 0 (time of bile salts addition) and every $30 \mathrm{~min}$ for a total of $60 \mathrm{~min}$ (quick digestion simulation) or for a total of $120 \mathrm{~min}$ (slow digestion simulation). Enumeration of survivors was done as described in Section 2.2.6. All assays were done in triplicate.

\subsection{Statistical Analysis}

Significant differences in the survival of LAB cultures previously grown into standard or modified MRS broth and stored under different conditions of temperature, $\mathrm{a}_{\mathrm{w}}$ and light, were tested by an analysis of variance (one-way ANOVA). Significant differences between slow and quick gastric transit simulations and digestions on the survival of microorganisms in simulated gastro-intestinal tract conditions were also investigated. Multiple comparisons were evaluated by Tukey's post hoc test. All calculations were carried out using the software KaleidaGraph (version 4.4, Synergy Software, Reading, PA, USA).

\section{Results}

\subsection{Spray Drying of Orange Juice Incorporated with $L A B$}

Cell counts observed for the two LAB before and after spray drying for all the growth conditions investigated as well as the $\mathrm{a}_{\mathrm{w}}$ values of the dried powders and the drying yield are presented in Table 1 .

Table 1. Survival of LAB isolates before and after spray drying (SD) in RSM or in orange juice with 10 DE maltodextrin (OJM) after grown in standard or modified MRS and the $\mathrm{a}_{\mathrm{w}}$ values of and yield of the respective powders.

\begin{tabular}{cccccc}
\hline \multirow{2}{*}{ LAB } & \multirow{2}{*}{ Condition } & \multicolumn{2}{c}{$\log \mathbf{c f u} / \mathbf{m L}^{\mathbf{a}}$} & \multicolumn{2}{c}{ Powder } \\
\cline { 3 - 5 } & & Before SD & After SD & $\mathbf{a}_{\mathbf{w}} \mathbf{b}^{\mathbf{b}}$ & Yield (\%) $^{\mathbf{c}}$ \\
\hline & MRS-Glucose + RSM & $9.9 \pm 0.12$ & $10.4 \pm 0.12$ & $0.383 \pm 0.125$ & $62.8 \pm 5.4$ \\
& MRS-Glucose + OJM & $9.4 \pm 0.03$ & $9.5 \pm 0.30$ & $0.421 \pm 0.076$ & $53.7 \pm 5.5$ \\
L. plantarum 299v & MRS-Fructose + OJM & $9.2 \pm 0.04$ & $9.6 \pm 0.12$ & $0.398 \pm 0.032$ & $43.8 \pm 5.7$ \\
& MRS-Sorbitol + OJM & $9.4 \pm 0.11$ & $9.1 \pm 0.39$ & $0.386 \pm 0.015$ & $38.9 \pm 6.0$ \\
& MRS-Lactose + OJM & $8.4 \pm 0.12$ & $7.9 \pm 0.57$ & $0.379 \pm 0.116$ & $48.4 \pm 6.6$ \\
& MRS-Sucrose + OJM & $8.2 \pm 0.33$ & $8.4 \pm 0.37$ & $0.374 \pm 0.054$ & $56.0 \pm 8.9$ \\
\hline & MRS-Glucose + RSM & $9.2 \pm 0.02$ & $10.3 \pm 0.03$ & $0.358 \pm 0.122$ & $61.5 \pm 1.2$ \\
& MRS-Glucose + OJM & $9.0 \pm 0.06$ & $9.4 \pm 0.23$ & $0.357 \pm 0.038$ & $53.8 \pm 8.6$ \\
P. acidilactici HA-6111-2 & MRS-Fructose + OJM & $9.4 \pm 0.12$ & $9.4 \pm 0.50$ & $0.488 \pm 0.095$ & $58.4 \pm 7.7$ \\
& MRS-Sorbitol + OJM & $8.6 \pm 0.24$ & $8.3 \pm 0.43$ & $0.372 \pm 0.052$ & $41.1 \pm 5.1$ \\
& MRS-Lactose + OJM & $8.7 \pm 0.05$ & $8.7 \pm 0.12$ & $0.392 \pm 0.045$ & $59.4 \pm 7.6$ \\
& MRS-Sucrose + OJM & $8.8 \pm 0.06$ & $8.9 \pm 0.19$ & $0.359 \pm 0.022$ & $65.8 \pm 6.4$ \\
\hline
\end{tabular}

${ }^{a}$ : Survival is represented as the mean of the $\log \mathrm{cfu} / \mathrm{mL} \pm$ the standard error of the mean; ${ }^{b}$ : The $\mathrm{a}_{\mathrm{w}}$ is represented as the mean of $a_{w}$ values \pm the standard error of the mean; ${ }^{c}$ : The powder yield is represented as the mean of percentages of powder obtained \pm the standard error of the mean.

Figures 1 and 2 show the survival of both LAB evaluated over 12 months at room temperature and exposed to light (graphs A1 to A6), at $4{ }^{\circ} \mathrm{C}$ and light exposure (graphs B1 to B6), at room temperature and in the absence of light (graphs $\mathrm{C} 1$ to $\mathrm{C} 6$ ), all with $\mathrm{a}_{\mathrm{w}}$ values controlled to 0.03 and, finally, at room temperature with light exposure and $\mathrm{a}_{\mathrm{w}}$ value controlled to 0.11 (graphs D1 to D6). 


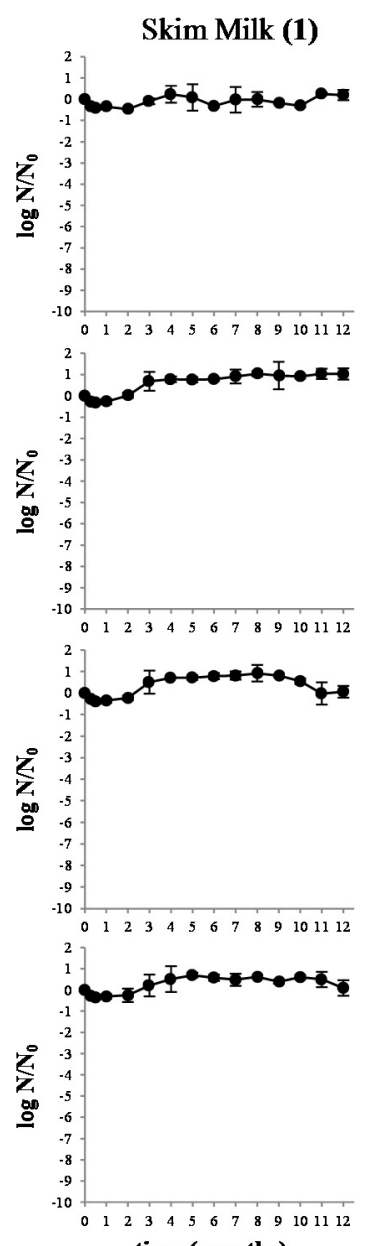

time (months)
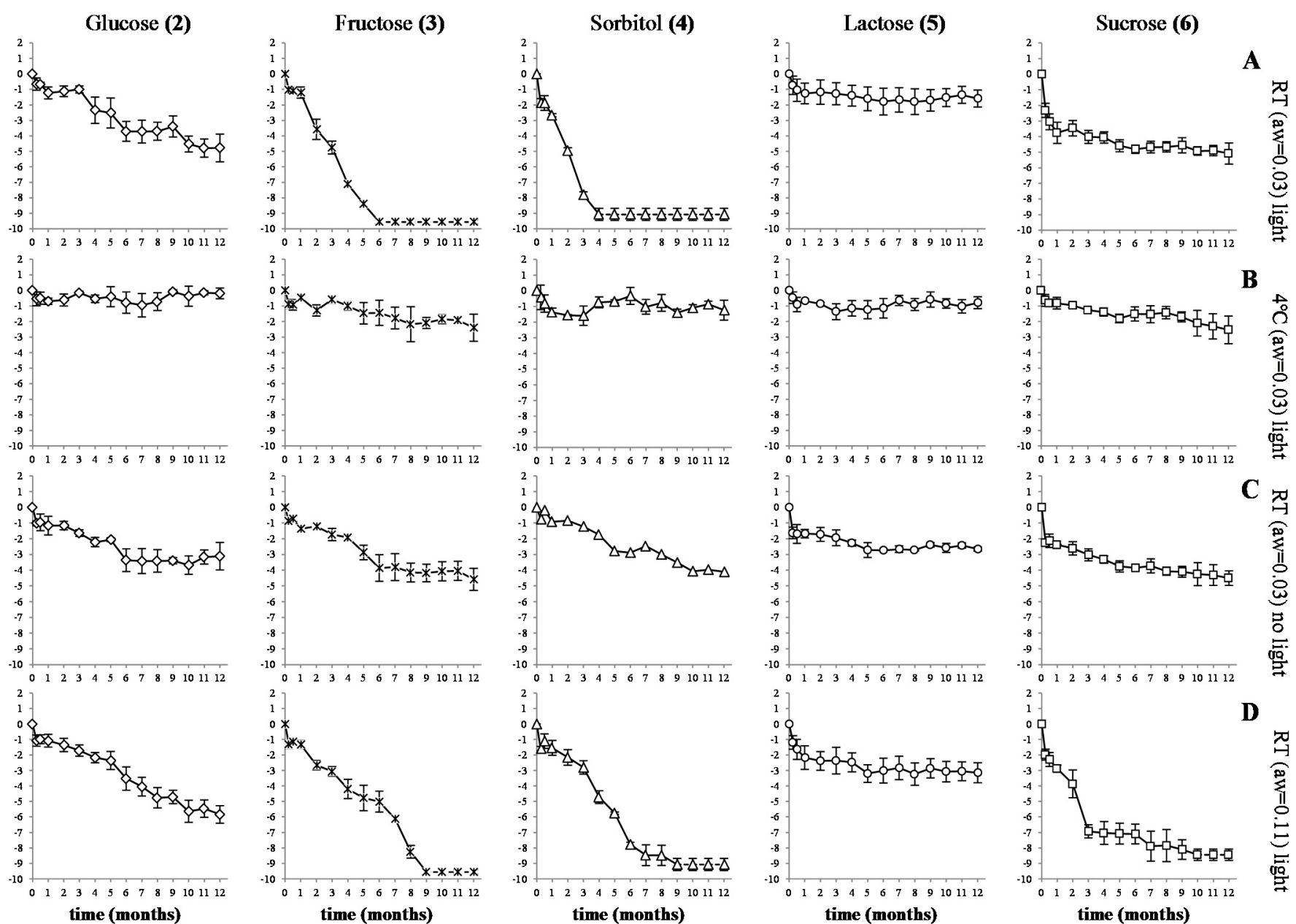

time (months)

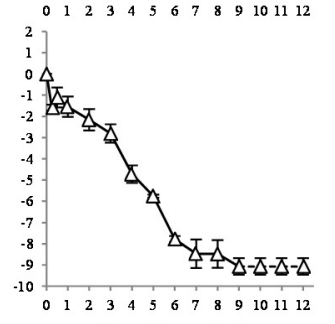

time (months)
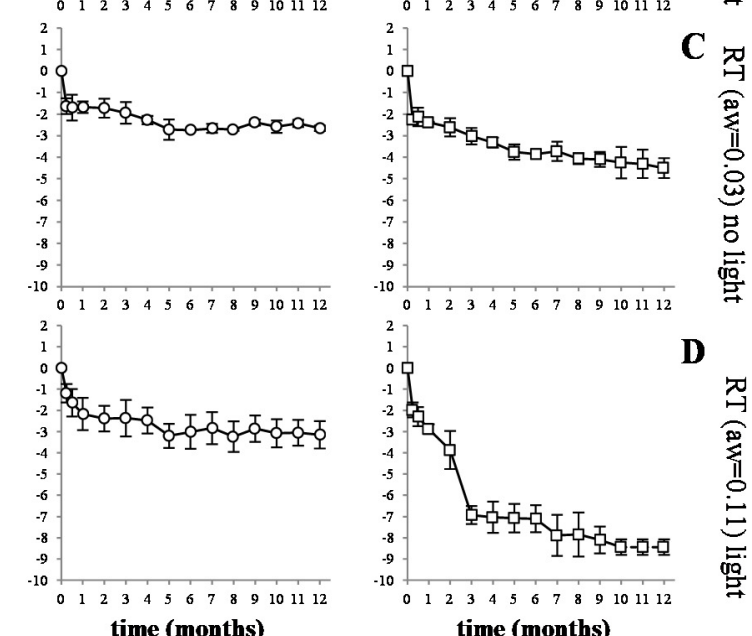

Figure 1. Logarithmic reduction of L. plantarum $299 \mathrm{v}$ incorporated in RSM or orange juice with $2 \%$ of 10 DE maltodextrin after spray drying and during 12 months of storage at different conditions (A-D): control (inoculum in 10\% $(w / v)$ of RSM); inoculum in orange juice with $2 \%$ of 10 DE maltodextrin after grown in MRS supplemented with $20 \mathrm{~g} / \mathrm{L}$ of different sugars $(2,3,4,5$ and 6$)$. The dotted lines mean that survival was lower than the detection limit of the enumeration technique. 

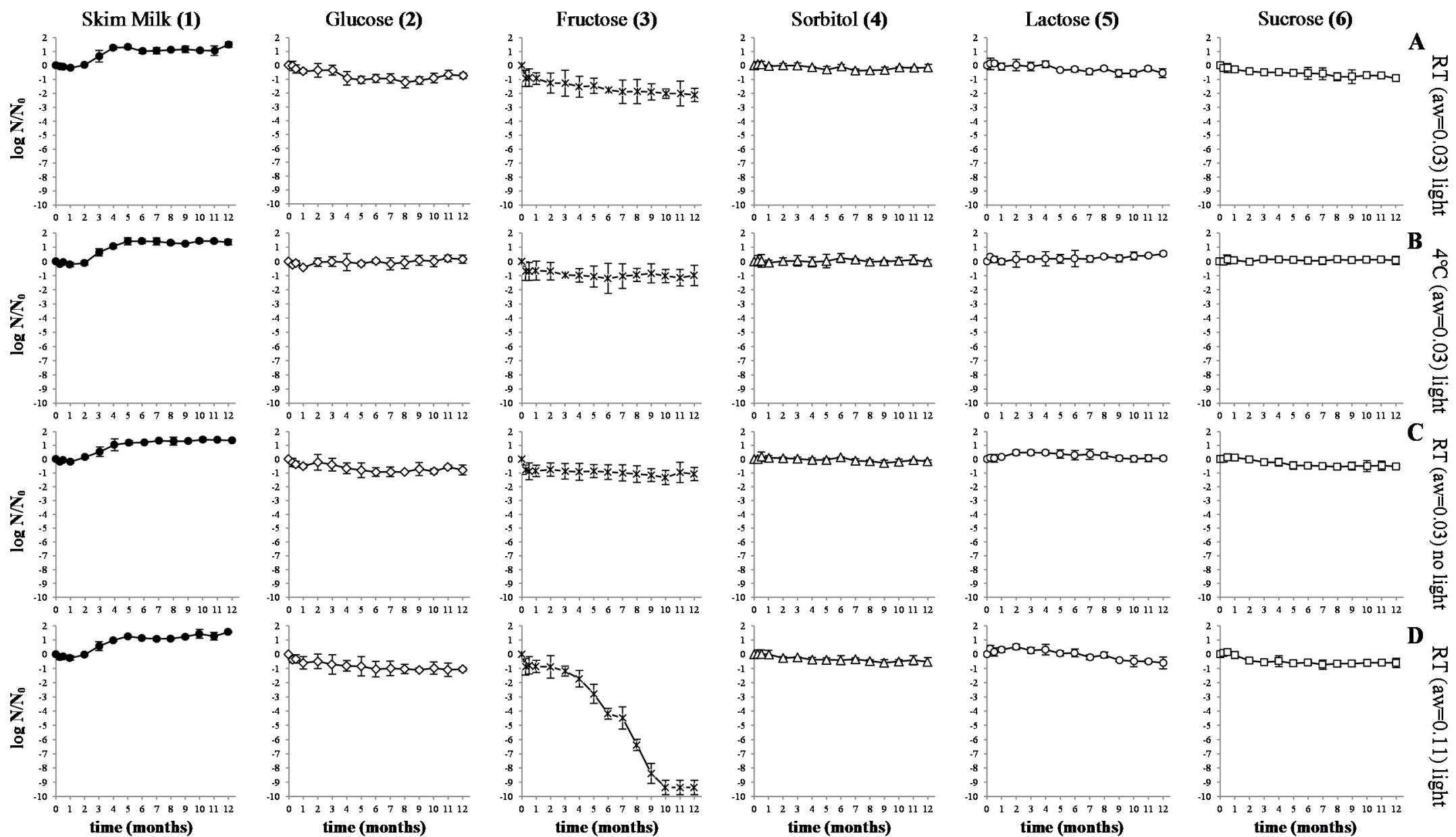

Figure 2. Logarithmic reduction of $P$. acidilactici HA-6111-2 incorporated in RSM or orange juice with $2 \%$ of 10 DE maltodextrin after spray drying and during 12 months of storage at different storage conditions (A-D): control (inoculum in $10 \%(w / v)$ of RSM); inoculum in orange juice with $2 \%$ of 10 DE maltodextrin after grown in MRS supplemented with $20 \mathrm{~g} / \mathrm{L}$ of different sugars $(2,3,4,5$ and 6$)$. The dotted lines mean that survival was lower than the detection limit of the enumeration technique. 
For all the storage conditions investigated, no significant $(p>0.001)$ reductions in cell viability were observed for both LAB after spray drying in RSM, used in this study as a control.

After spray drying in orange juice and subsequent storage at room temperature in the presence of light and $\mathrm{a}_{\mathrm{w}}$ controlled to 0.03 (Figure 1, graphs A2 to A6), the highest survival of L. plantarum $299 \mathrm{v}$ was observed for cells grown in MRS with lactose (1.6 log unit reduction), MRS with glucose (4.8 log unit reduction) and MRS with sucrose (5.1 log unit reduction). Pediococcus acidilactici HA-6111-2 showed logarithmic reductions of less than 1 log-unit for all conditions (Figure 2, graphs A2 to A6), except for cells grown in MRS containing fructose (2.1 log-unit reduction).

For both $\mathrm{LAB}$, stored at $4{ }^{\circ} \mathrm{C}$ under controlled $\mathrm{a}_{\mathrm{w}}$ (0.03; graphs $\mathrm{B} 2$ to $\left.\mathrm{B} 6\right)$, logarithmic reductions were minimal. The maximum reduction in cell viability of $P$. acidilactici HA-6111-2 (Figure 2) was observed for cells grown in MRS with fructose. For L. plantarum 299v (Figure 1), significant reductions in cell viability were only observed for cells grown in MRS with fructose or sucrose.

In the absence of light (graphs C2 to C6), with the exception of cells grown in the presence of lactose, for all the other sugars investigated, survival of L. plantarum $299 \mathrm{v}$ (Figure 1) increased. This effect was not demonstrated for P. acidilactici HA-6111-2 (Figure 2); no significant decrease in survival was observed when cells were stored at an $\mathrm{a}_{\mathrm{w}}$ controlled to 0.03 and in absence of light.

During storage at an $\mathrm{a}_{\mathrm{w}}$ controlled to 0.11 (graphs D2 to D6), for L. plantarum 299v (Figure 1.) only cells grown in MRS with lactose (3.1 log unit reduction) or glucose (5.8 log unit reduction) were not reduced to values below the detection limit of the technique. For P. acidilactici HA-6111-2, with the exception of fructose, there were no significant differences in the viability of cells grown in the presence of lactose, glucose, sorbitol or sucrose $(p>0.05)$.

Survival during storage at $\mathrm{a}_{\mathrm{w}}$ controlled to 0.03 (graphs A2 to A6) was significantly $(p<0.0001)$ higher than when cells were stored at an $\mathrm{a}_{\mathrm{w}}$ of 0.11 .

\subsection{Gastro-Intestinal Tract Simulation}

The conditions of the gastro-intestinal tract were simulated for both LAB at the end of storage at 4 ${ }^{\circ} \mathrm{C}$ and their logarithmic reductions are presented in Table 2.

Table 2. Survival of LAB isolates after 12 months of storage after spray-drying (SD) in RSM or in orange juice with $10 \mathrm{DE}$ maltodextrin, through quick and slow digestions simulations.

\begin{tabular}{ccccc}
\hline \multicolumn{5}{c}{$\log \left(\mathbf{N} / \mathbf{N}_{\mathbf{0}}\right)^{\mathbf{a}}$} \\
\hline \multicolumn{5}{c}{ Quick Digestion Simulation } \\
\hline LAB & Condition & 0 min & $60 \operatorname{min~}^{\mathrm{b}}$ & 120 min $^{\mathrm{c}}$ \\
\hline \multirow{2}{*}{ L. plantarum 299v } & SD in RSM & $0.00 \pm 0.00$ & $-0.24 \pm 0.18$ & $-1.38 \pm 0.15$ \\
& SD in orange juice & $0.00 \pm 0.00$ & $-0.51 \pm 0.29$ & $-2.02 \pm 0.45$ \\
\hline P. acidilactici & SD in RSM & $0.00 \pm 0.00$ & $-0.09 \pm 0.01$ & $-0.66 \pm 0.16$ \\
HA-6111-2 & SD in orange juice & $0.00 \pm 0.00$ & $-0.83 \pm 0.18$ & $-1.96 \pm 0.43$ \\
\hline \multicolumn{5}{c}{ Slow digestion simulation } \\
\hline L. plantarum 299v & SD in orange juice & $0.00 \pm 0.00$ & 120 min ${ }^{\mathrm{b}}$ & $240 \min ^{\mathrm{c}}$ \\
\hline P. acidilactici & SD in RSM & $0.00 \pm 0.00$ & $-0.15 \pm 0.10$ & $-1.35 \pm 0.45$ \\
HA-6111-2 & SD in orange juice & $0.00 \pm 0.00$ & $-0.10 \pm 0.07$ & $-2.31 \pm 0.27$ \\
\hline
\end{tabular}

a: Survival is represented as the mean of the logarithmic reduction: $\log \left(\mathrm{N} / \mathrm{N}_{0}\right) \pm$ the standard error of the mean; ${ }^{\text {b}}$ : Survival after exposure to $\mathrm{pH} 3.0$ in the presence of pepsin; ${ }^{\mathrm{c}}$ : Survival after exposure to $\mathrm{pH} 3.0$ in the presence of pepsin and subsequent exposure to bile salts at $\mathrm{pH} 7.0 ; \mathrm{N}: \mathrm{cfu} / \mathrm{mL}$ at each sampling time; $\mathrm{N}_{0}: \mathrm{cfu} / \mathrm{mL}$ at time zero.

For L. plantarum $299 \mathrm{v}$, there were no significant differences $(p>0.05)$ between cells dried in RSM and orange juice with maltodextrin, during both quick and long simulated digestions. However, 
the reduction was greater when the cells were subsequently exposed to bile salts than to $\mathrm{pH}$ of 3.0 with pepsin. For P. acidilactici HA-6111-2, the decrease was lower for cells dried in RSM, during both digestions $(p<0.05)$. Again, for orange juice with maltodextrin and RSM, the reduction was higher when the cells were exposed to the conditions of the small intestine digestion than to the acidic conditions of the stomach.

\section{Discussion}

\subsection{Spray Drying of Orange Juice Incorporated with $L A B$}

The drying process did not affect the number of L. plantarum 299v and P. acidilactici HA-6111-2 cells in all experiments as shown in Table 1.

It has been previously demonstrated that when L. plantarum 299v and P. acidilactici HA-6111-2 were spray dried in orange juice with $10 \mathrm{DE}$ maltodextrin and stored at room temperature without controlled $\mathrm{a}_{\mathrm{w}}$ survivors decreased to values below the detection limit of the enumeration technique after 60 days (L. plantarum 299v) or 120 days (P. acidilactici HA-6111-2). At $4{ }^{\circ} \mathrm{C}$, while P. acidilactici HA-6111-2 cells have been reduced by less than $1 \log$ unit, L. plantarum $299 \mathrm{v}$ decreased by $8 \log$ units after 210 days of storage [17]. Thus, in order to improve survival of these strains, in this study we investigated different storage temperatures (room and $4{ }^{\circ} \mathrm{C}$ ) and, at room temperature, we varied other conditions (the presence/absence of light and $\mathrm{a}_{\mathrm{w}}$ controlled to 0.03 or to 0.11 ).

For all the conditions investigated, the potential probiotic P. acidilactici HA-6111-2 proved to be more resistant than the commercial probiotic L. plantarum 299v. Other investigators had previously reported that resistance to spray drying is species/strain-dependent $[18,19]$.

It was also evident that the RSM, used in this study as a control, conferred a high protective effect, as observed in other studies [20,21].

The addition of sugars to the drying medium to improve survival of LAB during drying by different drying techniques has been reported by several authors [10,22]. Although the survival of these two LAB during spray drying in orange juice was demonstrated to be very low in previous studies [17], the addition of sugars to the juice was excluded as a potential alternative to improve survival as this would result in an increase in the viscosity of the juice with detrimental effects during the drying process. In addition to the use of maltodextrin, recognized as a good protectant during drying $[5,23]$, other factors were combined to increase the survival of LAB. It has been previously demonstrated that the addition of certain sugars to the media used for the growth of various LAB cultures influenced their survival during spray drying [11], lyophilization [10], and other drying methods [24]. This effect was also observed in the present study.

The logarithmic reductions of both LAB were minimal during storage at $4{ }^{\circ} \mathrm{C}$. It has been demonstrated that the highest survival of dried bacteria occurs at low storage temperatures [13], probably resulting from a lower rate of membrane fatty acid oxidation, i.e., lower formation of free radicals that enter and destroy the DNA, killing the cell [25].

The absence of light during storage resulted in an increasing survival of L. plantarum $299 \mathrm{v}$, comparing with the storage in the presence of light. Several authors have already mentioned the negative effects of light exposure on the survival of dried microorganisms, also related with membrane fatty acid oxidation $[8,12]$.

Survival of both LAB during storage at $\mathrm{a}_{\mathrm{w}}$ controlled to 0.03 was higher than when cells were stored at an $\mathrm{a}_{\mathrm{w}}$ of 0.11 . Abe et al. [26] also recorded better survival rates at lower $\mathrm{a}_{\mathrm{w}}$ values. However, Golowczyc et al. [22] reported higher survival rates at both $\mathrm{a}_{\mathrm{w}}$ values of 0.03 and 0.11 .

Growth in the presence of various sugars results in cells with different morphological and physiological characteristics, which leads to different behaviors to different stresses [27]. One possible explanation for this increase in resistance is related to the accumulation of compatible solutes by cells, which makes them more resistant to hyperosmotic stress. However, LAB cannot synthesize these compatible solutes (such as sugars) that favor the increase of viability during the drying processes [28]. 
Adding these solutes to the drying medium may not be sufficient, since the drying time is short. Thus, by growing the cells in contact with sugars, they have time to accumulate these compatible solutes [11]. Sugars may preserve the structures of the membrane, as well as delay protein denaturation [29].

Some differences in the results obtained by other authors when the same sugars were incorporated into the growth media, could be explained by the different species/strains, different drying techniques or the different drying media used. For example, Carvalho et al. [10] reported good survival of freeze-dried cells of L. delbrueckii ssp. bulgaricus during storage, after their growth in MRS containing fructose or lactose. In our study, cells grown in the presence of fructose demonstrated the lowest survival during storage. Similarly, Panoff et al. [30] found that growth of a L. delbrueckii ssp. bulgaricus strain in the presence of lactose and sucrose increased its survival during freezing and thawing. Also the growth of a L. sakei strain in the presence of sucrose enhanced its survival after spray drying [11]. Sorbitol also protected lyophilized cells of L. plantarum during storage, but only when this was incorporated in the drying medium [31]. After the incorporation of glucose into the drying medium, the survival of spray dried cells of L. rhamnosus during storage was improved [32]. Unlike the study by Carvalho et al. [10], the high survival rate during storage of the cells grown in MRS medium with glucose in our study, may be due not only to the fact that drying techniques were different, but also the storage conditions of the dried powders.

\subsection{Gastro-Intestinal Tract Simulation}

Since the viability of probiotics should be maintained not only in the food product, but also during the storage period and throughout passage of the gastro-intestinal tract of the consumer, the conditions of the gastro-intestinal tract were simulated after 12 months of storage to verify if both LAB could survive a quick or a slow digestion. As there were many variables, cells from cultures grown in MRS medium with glucose (high survival, after lactose, and sugar naturally embedded in MRS) and powders stored at $4{ }^{\circ} \mathrm{C}$ (longer survival of both microorganisms) and derived from orange juice with maltodextrin, were chosen. Powders stored at $4{ }^{\circ} \mathrm{C}$ and derived from the cultures dried in RSM, were used as a control.

The reduction was higher when the cells of both $\mathrm{LAB}$ were exposed to the conditions of the small intestine digestion than to the acidic conditions of the stomach. The ability to survive better in low $\mathrm{pH}$ rather than in the presence of bile salts was also reported for P. acidilactici [33] and L. plantarum [34] strains.

Several authors have shown that the survival of cells from different species, through a simulated gastro-intestinal tract, was enhanced, after being spray dried [19,35].

In summary, after 12 months of storage in orange juice, there was a reduction of approximately 2 log-unit for L. plantarum 299v and P. acidilactici HA-6111-2 during both the quick and the long simulated digestions. This result is important since after the storage period studied, the dried powders which have the minimum amount required of viable cultures in order to be considered a probiotic product $\left(\sim 10^{9} \mathrm{cfu} / \mathrm{mL}\right)$, suffer a reduction of only 2 log-units after gastro-intestinal passage, thereby presenting viable counts of these cultures of $\sim 10^{7} \mathrm{cfu} / \mathrm{mL}$, thus potentially exerting a beneficial effect on the health of the consumer.

\section{Conclusions}

From the present study we conclude that: (1) the use of carbohydrates such as lactose (or glucose) for the growth of LAB before spray drying in orange juice, could improve their ability to survive during the drying processes and during subsequent storage; (2) in addition to the high survival of both LAB studied, they were able to resist simulated conditions of the gastro-intestinal tract, even after 12 months of storage; and (3) storage conditions are very important and, although $4{ }^{\circ} \mathrm{C}$ was shown to be the best temperature, room temperature without light exposure also allowed a high survival when the $\mathrm{a}_{\mathrm{w}}$ was controlled to 0.03 , which was sugar-dependent. Costs of storage could be reduced by eliminating refrigerated storage and survival enhanced by a light-proof package. 
Thus, using the conditions of growth and storage mentioned above, it should be possible to produce an orange juice powder with probiotic characteristics with a shelf life date of at least 12 months in a package protected from daylight exposure.

Acknowledgments: This work was supported by National Funds from FCT-Fundação para a Ciência e a Tecnologia through project UID/Multi/50016/2013. Financial support for author J. Barbosa was provided by PhD fellowship, SFRH/BD/48894/2008 (FCT).

Author Contributions: Joana Barbosa did all the experimental work and drafted the manuscript. Sandra Borges helped in experimental work. Paula Teixeira helped in experimental design, critically reviewed the draft manuscript and provided substantive input.

Conflicts of Interest: The authors declare no conflict of interest.

\section{Abbreviations}

The following abbreviations are used in this manuscript:

$\begin{array}{ll}\text { CFU } & \text { Colony forming unit } \\ \text { LAB } & \text { Lactic acid bacteria } \\ \text { MRS } & \text { Man, Rogosa \& Sharpe } \\ \text { RSM } & \text { Reconstituted skim milk } \\ a_{\mathrm{w}} & \text { water activity } \\ \text { BPW } & \text { Buffered peptone water }\end{array}$

\section{References}

1. Ying, D.; Schwander, S.; Weerakkody, R.; Sanguansri, L.; Gantenbein-Demarchi, C.; Augustin, M.A. Microencapsulated Lactobacillus rhamnosus GG in whey protein and resistant starch matrices: Probiotic survival in fruit juice. J. Funct. Foods 2013, 5, 98-105. [CrossRef]

2. Granato, D.; Branco, G.F.; Nazzaro, F.; Cruz, A.G.; Faria, J.A.F. Functional foods and non-dairy probiotic product food development: Trends, concepts and products. Compr. Rev. Food Sci. Food Saf. 2010, 9, 292-302. [CrossRef]

3. Silva, J.; Freixo, R.; Gibbs, P.; Teixeira, P. Spray-drying for the production of dried cultures. Int. J. Dairy Technol. 2011, 64, 321-335. [CrossRef]

4. Bhandari, B.R.; Senoussi, A.; Dumoulin, E.D.; Lebert, A. Spray drying of concentrated fruit juices. Dry. Technol. 1993, 11, 1081-1092. [CrossRef]

5. Anekella, K.; Orsat, V. Optimization of microencapsulation of probiotics in raspberry juice by spray drying. LWT Food Sci. Technol. 2013, 50, 17-24. [CrossRef]

6. Tonon, R.V.; Brabet, C.; Hubinger, M.D. Anthocyanin stability and antioxidant activity of spray-dried acai (Euterpe oleracea Mart.) juice produced with different carrier agents. Food Res. Int. 2010, 43, 907-914. [CrossRef]

7. Slavin, J. Fiber and Prebiotics: Mechanisms and Health Benefits. Nutrients 2013, 5, 1417-1435. [CrossRef] [PubMed]

8. Tripathi, M.K.; Giri, S.K. Probiotic functional foods: Survival of probiotics during processing and storage. J. Funct. Foods 2014, 9, 225-241. [CrossRef]

9. Food and Agriculture Organization/World Health Organization. Guidelines for the Evaluation of Probiotics in Food: Report of a Joint FAO/WHO Working Group on Drafting Guidelines for the Evaluation of Probiotics in Food; FAO/WHO: London, ON, Canada, 2002.

10. Carvalho, A.S.; Silva, J.; Ho, P.; Teixeira, P.; Malcata, F.X.; Gibbs, P. Effects of various sugars added to growth and drying media upon thermotolerance and survival throughout storage of freeze-dried Lactobacillus delbrueckii ssp. bulgaricus. Biotechnol. Progr. 2004, 20, 248-254. [CrossRef] [PubMed]

11. Ferreira, V.; Soares, V.; Santos, C.; Silva, J.; Gibbs, P.A.; Teixeira, P. Survival of L. sakei during heating, drying and storage in the dried state when growth has occurred in the presence of sucrose or monosodium glutamate. Biotechnol. Lett. 2005, 27, 249-252. [CrossRef] [PubMed] 
12. Strasser, S.; Neureiter, M.; Geppl, M.; Braun, R.; Danner, H. Influence of lyophilization, fluidized bed drying, addition of protectants, and storage on the viability of lactic acid bacteria. J. Appl. Microbiol. 2009, 107, 167-177. [CrossRef] [PubMed]

13. Teixeira, P.C.; Castro, M.H.; Malcata, F.X.; Kirby, R.M. Survival of Lactobacillus delbrueckii ssp. bulgaricus following spray-drying. J. Dairy Sci. 1995, 78, 1025-1031.

14. Barbosa, J.; Borges, S.; Teixeira, P. Pediococcus acidilactici as a potential probiotic to be used in food industry. Int. J. Food Sci. Technol. 2015, 50, 1151-1157.

15. Miles, A.A.; Misra, S.S. The estimation of the bactericidal power of blood. J. Hyg. 1938, 38, 732-749. [CrossRef] [PubMed]

16. Barbosa, J.; Borges, S.; Magalhães, R.; Ferreira, V.; Santos, I.; Silva, J.; Almeida, G.; Gibbs, P.; Teixeira, P. Behaviour of Listeria monocytogenes isolates through gastro-intestinal tract passage simulation, before and after two sub-lethal stresses. Food Microbiol. 2012, 30, 24-28. [CrossRef] [PubMed]

17. Barbosa, J.; Borges, S.; Teixeira, P. Spray drying conditions for orange juice incorporated with lactic acid bacteria. Int. Food Res. J. 2016. in press.

18. Corcoran, B.M.; Ross, R.P.; Fitzgerald, G.F.; Stanton, C. Comparative survival of probiotic lactobacilli spray-dried in the presence of prebiotic substances. J. Appl. Microbiol. 2004, 96, 1024-1039. [CrossRef] [PubMed]

19. Páez, R.; Lavari, L.; Vinderola, G.; Audero, G.; Cuatrin, A.; Zaritzky, N.; Reinheimer, J. Effect of heat-treatment and spray drying on lactobacilli viability and resistance to simulated gastrointestinal digestion. Food Res. Int. 2012, 48, 748-754. [CrossRef]

20. Ananta, E.; Volkert, M.; Knorr, D. Cellular injuries and storage stability of spray-dried Lactobacillus rhamnosus GG. Int. Dairy J. 2005, 15, 399-409. [CrossRef]

21. Fritzen-Freire, C.B.; Prudencio, E.S.; Amboni, R.D.M.C.; Pinto, S.S.; Negrao-Murakami, A.N.; Murakami, F.S. Microencapsulation of bifidobacteria by spray drying in the presence of prebiotics. Food Res. Int. 2012, 45, 306-312. [CrossRef]

22. Golowczyc, M.A.; Gerez, C.L.; Silva, J.; Abraham, A.G.; De Antoni, G.L.; Teixeira, P. Survival of spray-dried Lactobacillus kefir is affected by different protectants and storage conditions. Biotechnol. Lett. 2011, 33, 681-686. [CrossRef] [PubMed]

23. Reddy, K.B.P.K.; Madhu, A.N.; Prapulla, S.G. Comparative survival and evaluation of functional probiotic properties of spray-dried lactic acid bacteria. Int. J. Dairy Technol. 2009, 62, 240-248. [CrossRef]

24. Tymczyszyn, E.E.; Gomez-Zavaglia, A.; Disalvo, E.A. Effect of sugars and growth media on the dehydration of Lactobacillus delbrueckii ssp. bulgaricus. J. Appl. Microbiol. 2007, 102, 845-851. [CrossRef] [PubMed]

25. Castro, H.P.; Teixeira, P.M.; Kirby, R. Storage of lyophilized cultures of Lactobacillus bulgaricus under different relative humidities and atmospheres. Appl. Microbiol. Biotechnol. 1995, 44, 172-176. [CrossRef]

26. Abe, F.; Miyauchi, H.; Uchijima, A.; Yaeshima, T.; Iwatsuki, K. Effects of storage temperature and water activity on the survival of bifidobacteria in powder form. Int. J. Dairy Technol. 2009, 62, 234-239. [CrossRef]

27. Carvalho, A.S.; Silva, J.; Ho, P.; Teixeira, P.; Malcata, F.X.; Gibbs, P. Relevant factors for the preparation of freeze-dried lactic acid bacteria. Int. Dairy J. 2004, 14, 835-847. [CrossRef]

28. Morgan, C.A.; Herman, N.; White, P.A.; Vesey, G. Preservation of micro-organisms by drying; a review. J. Microbiol. Methods 2006, 66, 183-193. [CrossRef] [PubMed]

29. Chávez, B.E.; Ledeboer, A.M. Drying of probiotics: optimization of formulation and process to enhance storage survival. Dry. Technol. 2007, 25, 1193-1201. [CrossRef]

30. Panoff, J.M.; Thammavongs, B.; Gueguen, M. Cryoprotective lead to phenotypic adaptation to freeze-thaw stress in Lactobacillus delbrueckii ssp. bulgaricus. Cryobiology 2000, 40, 264-269. [CrossRef] [PubMed]

31. Carvalho, A.S.; Silva, J.; Ho, P.; Teixeira, P.; Malcata, F.X.; Gibbs, P. Effect of additives on survival of freeze-dried Lactobacillus plantarum and Lactobacillus rhamnosus during storage. Biotechnol. Lett. 2002, 24, 1587-1591. [CrossRef]

32. Ying, D.; Sun, J.; Sanguansri, L.; Weerakkody, R.; Augustin, M.A. Enhanced survival of spray-dried microencapsulated Lactobacillus rhamnosus GG in the presence of glucose. J. Food Eng. 2012, 109, 597-602. [CrossRef]

33. Abbasiliasi, S.; Tan, J.S.; Ibrahim, T.A.T.; Ramanan, R.N.; Vakhshiteh, F.; Mustafa, S.; Ling, T.C.; Rahim, R.A.; Ariff, A.B. Isolation of Pediococcus acidilactici Kp10 with ability to secrete bacteriocin-like inhibitory substance from milk products for applications in food industry. BMC Microbiol. 2012, 12, 260-271. [CrossRef] [PubMed] 
34. Mirlohi, M.; Soleimanian-Zad, S.; Dokhani, S.; Sheikh-Zeinodin, M.; Abghary, A. Investigation of acid and bile tolerance of native lactobacilli isolated from fecal samples and commercial probiotics by growth and survival studies. Iran. J. Biotech. 2009, 7, 233-240.

35. Maciel, G.M.; Chaves, K.S.; Grosso, C.R.F.; Gigante, M.L. Microencapsulation of Lactobacillus acidophilus La- 5 by spray-drying using sweet whey and skim milk as encapsulating materials. J. Dairy Sci. 2014, 97, 1991-1998. [CrossRef] [PubMed]

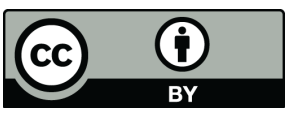

(C) 2016 by the authors; licensee MDPI, Basel, Switzerland. This article is an open access article distributed under the terms and conditions of the Creative Commons by Attribution (CC-BY) license (http://creativecommons.org/licenses/by/4.0/). 